\title{
Influence of Different Ground Thermal Properties in a Borehole Heat Exchanger's Performance Using the B2G Dynamic Model
}

\author{
Antonio Cazorla-Marín \\ Julio Martos
}

\author{
Carla Montagud \\ José Miguel Corberán
}

\author{
Álvaro Montero
}

\begin{abstract}
Ground source beat pump (GSHP) systems for heating and cooling represent an efficient alternative to conventional air source beat pump systems, always provided that they present an efficient design and operation. In this context, the development of energy optimization strategies becomes essential, with the aid of integrated dynamic models of the system, specially the ground source heat exchanger.

In previous works, a single $U$ borehole heat exchanger (BHE) dynamic model, called Borehole-to-Ground (B2G), was developed and experimentally validated. The B2G model is based on the thermal network approach, combined with a vertical discretization of the borehole. However, the thermal properties of the surrounding ground were modelled as an average, constant with depth. For homogeneous type of soils, this assumption might be acceptable but, when considering heterogeneous type of soils, modelling the presence of different layers with different materials could provide more accurate results.

In this work, the B2G model has been adapted in order to account for the effect of a heterogeneous ground profile on the fluid temperature evolution along the borehole depth. Experimental data corresponding to a Thermal Response Test (TRT) performed in a real BHE existing at the Universitat Politècnica de València, were used to validate this new feature of the B2G model. Finally, it is concluded that the model can serve as a ground thermal properties estimation tool.
\end{abstract}

\section{INTRODUCTION}

Ground properties needed for the design of Ground-Source Heat Pump (GSHP) systems are estimated with a standard method, the Thermal Response Test (TRT). After injecting or extracting a constant heat power, the test analyzes the ground thermal response with a few measurements, inlet and outlet temperatures of the fluid at the top of the borehole heat exchanger (BHE) and fluid mass flow rate. Effective ground thermal conductivity, borehole thermal resistance and undisturbed ground temperature are outputs of this test. In this context, models able to predict the BHE thermal performance can contribute to analyze this type of tests and to determine such outputs. In the last years, several approaches have been proposed in order to reproduce the thermal behavior of different BHE configurations (a complete review is reported by Yang, et al. (2010)). In general, models analyzing this data assume that ground 
thermophysical properties are homogeneous and isotropic; therefore, this approach is only able to estimate an effective ground thermal conductivity representing an average of the thermal conductivity of the different layers crossed by the perforation. As pointed in Aranzabal, et al. (2016), if a thermal conductivity profile of the ground as a function of depth is to be estimated, two additional inputs are needed; first, a measurement of the borehole temperature profile and, second, an analysis procedure taking into account that the ground is not homogeneous. In Aranzabal, et al. (2016) an analysis procedure, complementing the standard TRT analysis, was presented to estimate the thermal conductivity profile from a temperature profile along the borehole during the test. The analysis procedure was implemented by a 3D Finite Element Model (FEM) in which depth depending thermal conductivity of the subsoil was estimated by fitting simulation results with experimental data. The methodology was evaluated by the recorded temperature profiles throughout a TRT in a BHE monitored facility.

It should be noted that the influence of the different conductivity layers might be relevant for the short-term, and it has less influence in the modelling of the long term behaviour, as pointed out by Lee (2011) who stated that the adoption of an effective ground thermal conductivity and an effective ground volumetric heat capacity for a multi-layer ground determined from a TRT analysis led to very little error in the simulated long term system performance with differences lower than $0.5 \mathrm{~K}$. This effect will also be investigated in the present research work.

On the other hand, recent studies highlight the possibility of using dynamic simulation models to assist the determination of the ground effective thermal conductivity. In this context, Pasquier (2015) presented a program designed to analyze thermal response tests by deterministic or stochastic inversion, for single U BHEs with a thermal resistance and capacity model, which aims to foster investigation of new testing strategies with a possible reduction in the tests duration. The present contribution shows an alternative analysis procedure based on the recently developed borehole-to-ground (B2G) model, which is a thermal resistance and capacity model (5C6R), specially addressed to describe short term thermal processes in BHEs (Ruiz-Calvo, et al. (2015)). A new feature was included in the model to consider different ground layers in non homogeneous type of soil. Using the same experimental data analyzed in Aranzabal, et al. (2016), and the thermal conductivity profile estimated in that contribution, the purpose of this analysis is to experimentally validate and check the ability of the B2G model to reproduce the evolution of the measured ground temperature profile. This analysis is a first step towards the use of the B2G model as a complementary method to analyze TRT data in shorter time periods and adapted to non homogeneous type of soils.

\section{B2G MODEL}

\section{Model Description}

The Borehole-to-Ground(B2G) dynamic model was developed at the Instituto de Ingeniería Energética (IIE) Universitat Politècnica de València in order to reproduce the short-term performance of a single U-tube BHE during the daily injection/extraction of heat in an on/off GSHP system operation. It is able to calculate the instantaneous evolution of the fluid temperature taking into account the geometrical characteristics of the BHE and the thermophysical properties of the grout and the surrounding ground. This model has been presented and validated against experimental TRT data from different BHEs located at Universitat Politècnica de València, Spain (De Rosa, et al. 2015) and in Stockholm, Sweden (Ruiz-Calvo, et al. 2015). It has also been validated against experimental data from a GSHP system on/off operation during one month (Ruiz-Calvo, et al. 2016) and one year (Ruiz-Calvo 2015). For this purpose, the B2G model was coupled with the $\mathrm{g}$-function model in order to also predict the long-term response of the BHE.

The BHE is discretized vertically in several divisions; in each z-depth, a 2D thermal network represents the heat transfer between the different parts of the BHE. This thermal network is made of five nodes, each node represents one part of the BHE: $T_{1}$ represents the downward pipe fluid, $T_{2}$ represents the upward pipe fluid, the grout of the borehole is divided in two zones $\left(T_{b 1}\right.$ and $\left.T_{b 2}\right)$ and the surrounding ground is represented by $T_{g}$. The nodes are interconnected with thermal resistances that consider the conductive and convective heat transfer between the different parts of the $\mathrm{BHE}$ and each node includes the thermal capacitance of its part, representing its thermal inertia. Figure 1 (a) shows the 
thermal network of the BHE,where the different nodes and thermal resistances are represented.

Initially, the B2G model was developed to reproduce the instantaneous behavior of the BHE, for this purpose, only the portion of ground directly affected during the desired heat injection/extraction time is considered (around 10 hours for a normal on/off GSHP system operation). However, it is able to reproduce longer periods of injection/extraction of heat if a larger portion of ground is considered (and thus a higher thermal capacity of the ground). In this case, the accuracy of the short-term behavior decreases. In order to consider the corresponding amount of ground, a ground penetration diameter $\left(D_{g p}\right)$ is set and it defines the position of the ground node.

The original B2G model neglected the vertical conduction, although the advection in vertical direction for the fluid nodes was taken into account in the transient energy balance equations (Ruiz-Calvo, et al. 2015). The entire model results in $n$ thermal networks ( $n$ represents the number of vertical divisions of the BHE). At each depth, 5 thermal capacitances and 6 thermal resistances are considered (a 5C6R-n model), the thermal properties of the ground, the grout and the pipes are also taken into account. The model can be solved by numerical procedures, solving the system of ordinary differential equations as described in (Ruiz-Calvo, et al. 2015), where the model is described in more detail.

\section{Adaptation to heterogeneous ground}

Initially, the B2G dynamic model considered a homogeneous ground, so it used an effective ground thermal conductivity and an effective ground volumetric heat capacity if the ground was heterogeneous. This work is focused on the adaptation of the B2G model in order to consider different thermal conductivities in a multi-layer ground. In order to achieve this, an array of ground thermal conductivities depending on the depth is introduced in the model. Furthermore, the vertical conduction in the grout and ground zones is taken into account by means of vertical thermal resistances between the nodes of adjacent thermal networks, as it is shown in Figure 1 (b). The vertical thermal resistance

of the grout nodes is described in equation (1). It depends on the vertical thermal conductivity of the grout $\left(k_{b, v}\right)$, the vertical distance between nodes $(d z)$ and the grout horizontal surface $\left(D_{b}\right.$ represents the borehole diameter and $D_{p, e}$ is the external pipe diameter of the U-tube).

$$
R_{v b 1}=R_{v b 2}=\frac{d z}{\frac{\pi}{8} \cdot\left(D_{b}^{2}-2 \cdot D_{p, e}^{2}\right) \cdot k_{b, v}}
$$

Analogously, the vertical thermal resistance of the ground nodes is described in equation (2). In this case, the vertical thermal conductivity of the ground $\left(k_{g, v}\right)$ varies with the depth.

$$
R_{v g}(z)=\frac{d z}{\frac{\pi}{4} \cdot\left(D_{g p}^{2}-D_{b}^{2}\right) \cdot k_{g, v}(z)}
$$


a)

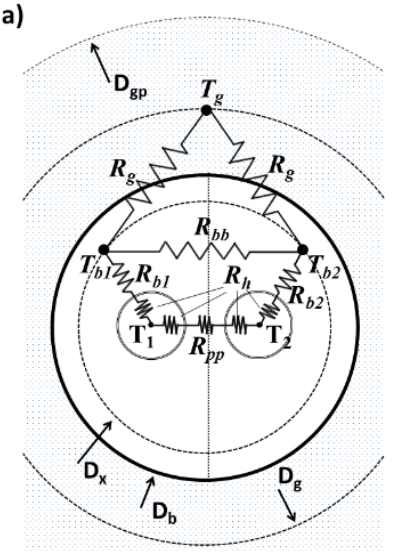

b)

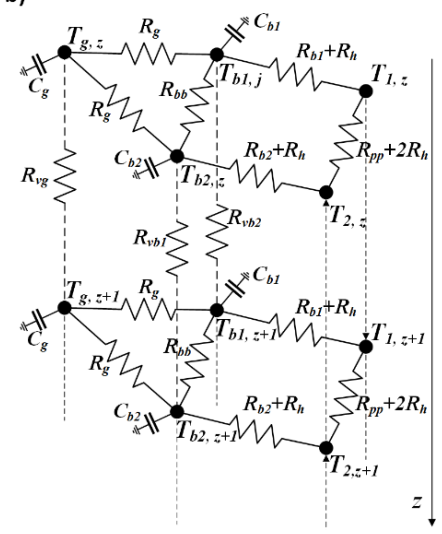

Figure 1 Thermal network of the B2G model: a) 2D model; b) 3D model

Now, the energy balance equations corresponding to the different nodes of the thermal network are presented in equations (3)-(7).

$$
\begin{gathered}
\frac{\partial T_{1}(z)}{\partial t}=-v \frac{\partial T_{1}(z)}{\partial z}-\frac{1}{C_{f}}\left(\frac{T_{1}(z)-T_{b 1}(z)}{R_{b 1}}+\frac{T_{1}(z)-T_{2}(z)}{R_{p p}}\right) \\
\frac{\partial T_{2}(z)}{\partial t}=-v \frac{\partial T_{2}(z)}{\partial z}-\frac{1}{C_{f}}\left(\frac{T_{2}(z)-T_{b 2}(z)}{R_{b 2}}-\frac{T_{1}(z)-T_{2}(z)}{R_{p p}}\right) \\
C_{b 1} \frac{\partial T_{b 1}(z)}{\partial t}=\frac{T_{1}(z)-T_{b 1}(z)}{R_{b 1}}+\frac{T_{b 2}(z)-T_{b 1}(z)}{R_{b b}}+\frac{T_{g}(z)-T_{b 1}(z)}{R_{g}(z)}+\frac{T_{b 1}(z-1)-T_{b 1}(z)}{R_{v b 1}}+\frac{T_{b 1}(z+1)-T_{b 1}(z)}{R_{v b 1}} \\
C_{b 2} \frac{\partial T_{b 2}(z)}{\partial t}=\frac{T_{2}(z)-T_{b 2}(z)}{R_{b 2}}+\frac{T_{b 1}(z)-T_{b 2}(z)}{R_{b b}}+\frac{T_{g}(z)-T_{b 2}(z)}{R_{g}(z)}+\frac{T_{b 2}(z-1)-T_{b 2}(z)}{R_{v b 2}}+\frac{T_{b 2}(z+1)-T_{b 2}(z)}{R_{v b 2}} \\
C_{g} \frac{\partial T_{g}(z)}{\partial t}=\frac{T_{b 1}(z)-T_{g}(z)}{R_{g}(z)}+\frac{T_{b 2}(z)-T_{g}(z)}{R_{g}(z)}+\frac{T_{g}(z-1)-T_{g}(z)}{R_{v g}(z)}+\frac{T_{g}(z+1)-T_{g}(z)}{R_{v g}(z)}
\end{gathered}
$$

The ground penetration diameter that sets the position of the ground nodes is calculated using an effective ground thermal conductivity and volumetric thermal capacity. For this purpose, the heat transfer equation for a region bounded internally by a circular cylinder and constant heat flux in its surface (Carslaw and Jaeger 1959) is used; this equation considers the period of time of heat injection/extraction and the thermal properties of the ground. The ground node $\left(D_{g}\right)$ is placed at the mean diameter between the penetration diameter $\left(D_{g p}\right)$ and the borehole diameter $\left(D_{b}\right)$ Regarding the position of the grout nodes $\left(D_{x}\right)$, they can be placed between the equivalent diameter of the pipes $\left(D_{e q}\right)$ and the borehole diameter $\left(D_{b}\right)$. To calculate the equivalent diameter, the Pasquier and Marcotte (2012) approach is used.

$$
D_{e q}=D_{p, e} \sqrt{\frac{4 W}{\pi D_{p, e}}+1}
$$

In this equation, $W$ represents the shank space between pipes. 


\section{THE BOREHOLE HEAT EXCHANGER AND EXPERIMENTAL DATA}

At the Universidad Politécnica de Valencia campus there exists a BHE of $40 \mathrm{~m}$ depth, $160 \mathrm{~mm}$ drill diameter and two geothermal independent pipes, ALB GEROtherm PE-100 of $40 \mathrm{~mm}$ diameter and 29 and $39 \mathrm{~m}$ long, respectively. The pipes are disposed with a turn of $90^{\circ}$ between them; keeping uniform the distance between the pipes of the geothermal probes with separators of polyethylene distributed every meter depth. A scheme of the facilty is shown in Figure 2. Further information about the facility can be found in Aranzabal, et al. (2016).

\section{THERMAL RESPONSE DATA}

Same data analyzed in Aranzabal, et al. (2016) are used in this contribution. The TRT started on 9th March 2011 at 11:00 with $1 \mathrm{~kW}$ heat injection, using the geothermal pipe of 29 meters deep, and leaving the one of 39 meters filled with water in order to use it as an observer pipe and to measure the temperature profile during the TRT. From the beginning of the TRT, the temperature profile was obtained in one of the 39 meters pipe, which was not used in this TRT for heat exchanging. Details of the measured data can be found in the work by Aranzabal, et al. (2016).

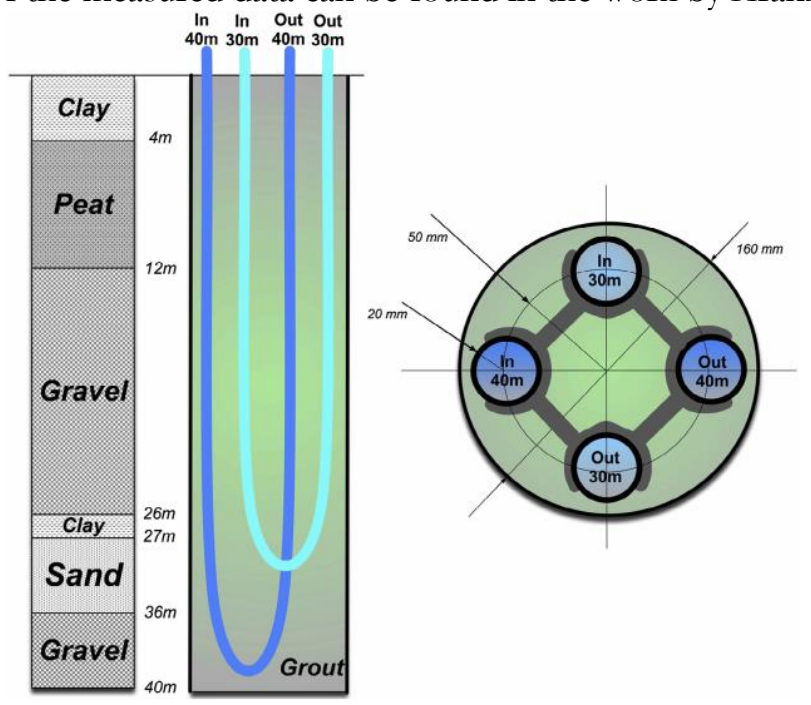

Figure 2 Scheme of the borehole heat exchanger facility, vertical layout on left figure and horizontal section on the right figure (Aranzabal, et al. 2016).

\section{EXPERIMENTAL VALIDATION FOR HETEROGENEOUS GROUND}

In order to validate the adaptation of the B2G dynamic model to consider a multi-layer ground, the test conducted in the borehole located at Universitat Politècnica de València (explained in the previous sections) was used. Furthermore, the ground conductivities along the borehole depth calculated in Aranzabal, et al. (2016) were used as inputs in the model. The B2G model has been developed for a single U-tube BHE configuration while the borehole used for the experiments is a double U-tube BHE. However, only one tube is used in the TRT, while the other one is used as an observer tube to measure the temperature evolution along the borehole depth. So, the B2G model is used to calculate the temperatures along the borehole depth on the grout nodes and to compare them with the measured temperatures from the observer tube. The position of the grout nodes has been set based on the grout temperature distribution maps in Esen, et al. (2009) to simulate the position of the observer tube. Regarding the observer tube, a maximum of $2 \mathrm{~K}$ temperature difference along the depth of the BHE was observed. Therefore, the natural convection flows due to the temperature difference between the top and the end of the BHE are considered negligible. The main parameters adopted 
in the simulations are shown in Table 1 . The number of vertical nodes that have been used is 117 , in order to obtain a good accuracy and a low computational time. The same ground thermal conductivity is considered in the vertical and radial direction for each depth. The mass flow rate and the temperature of the inlet fluid is introduced in the model as an input. The model calculates the temperature of the outlet fluid and the temperature in all the grout nodes for each simulation step.

Table 1 Main Parameters Adopted In The Model

\begin{tabular}{cccc}
\hline \multicolumn{2}{c}{ Thermo-physical properties } & Geometrical characteristics \\
\hline \hline Ground thermal conductivity & (See Figure 4) & Depth & $29 \mathrm{~m}$ \\
Grout thermal conductivity & $1 \mathrm{~W} / \mathrm{m} \cdot \mathrm{K}$ & Borehole diameter & $0.16 \mathrm{~m}$ \\
Ground volumetric thermal capacitance & $3600 \mathrm{~kJ} / \mathrm{m}^{3} \cdot \mathrm{K}$ & Inner diameter of the pipes & $0.0326 \mathrm{~m}$ \\
Grout volumetric thermal capacitance & $2500 \mathrm{~kJ} / \mathrm{m}^{3} \cdot \mathrm{K}$ & Outer diameter of the pipes & $0.04 \mathrm{~m}$ \\
Fluid & water & Shank space & $0.1 \mathrm{~m}$ \\
\hline
\end{tabular}

In order to compare the results obtained by the B2G model with the experimental measurements, four simulations have been carried out: for an injection time of 2.5 hours (9th March 2011 13:30h), 24 hours (10 th March 2011 11:00h), 48 hours (11 th March 2011 11:00h), and 72 hours (12 th March 2011 11:00h). The TRT results for the simulation of 72 hours of heat injection are presented in Figure 3, considering a homogeneous ground with a single fixed effective conductivity and initial temperature (Figure 3 (a)) and considering a multi-layer ground with different conductivities and initial temperatures (Figure 3 (b)). It can be seen that the outlet temperature calculated by the B2G model is very similar to the experimental one in both cases, although the accuracy in case (b) is slightly higher (the root mean square error of case (a) is $0.16 \mathrm{~K}$ and in case (b), it is $0.13 \mathrm{~K}$ ). The accuracy of the results is lower during the first hours of the simulation due to the fact that it has been used a penetration diameter according to a heat injection of 72 hours, losing accuracy in the first hours of the simulation, because the amount of ground considered (and thus the ground thermal capacity) is too high for the short-term response.
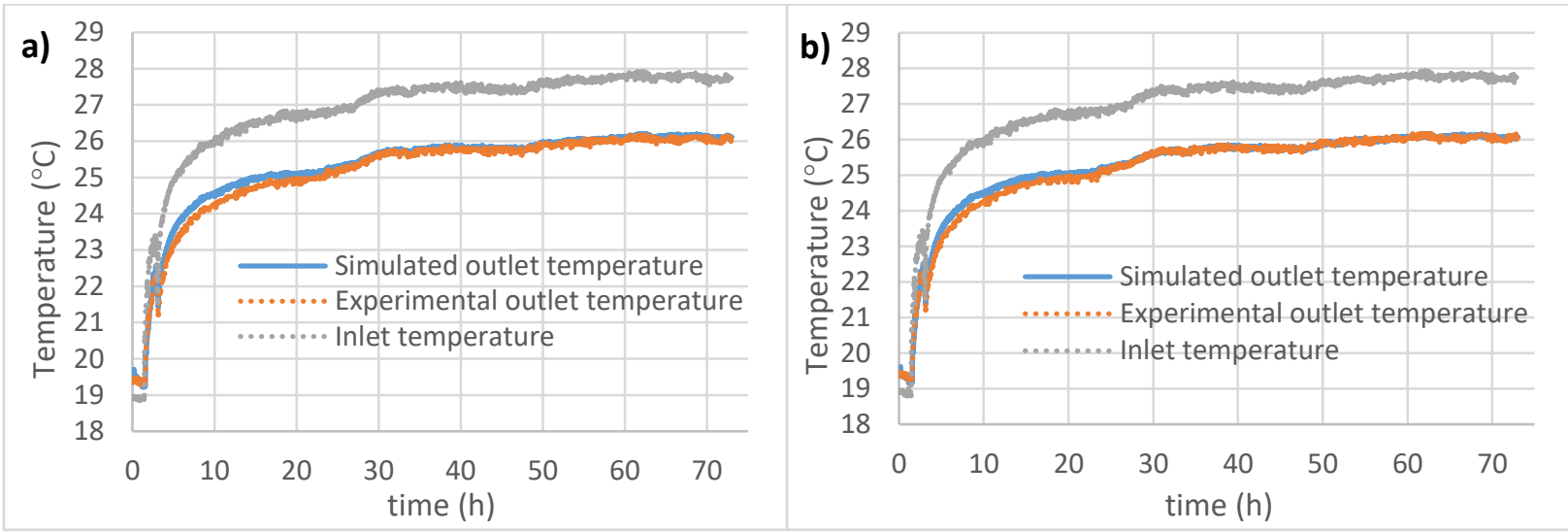

Figure 3 Comparison between the experimental measures and the results calculated by the B2G model for a TRT during 72 hours of heat injection. a) homogeneous ground; b) heterogeneous multi-layer ground.

Figure 4 shows a comparison between the experimental temperature measurements inside the observer tube and the simulated temperature of the grout nodes that has been calculated in the four simulations, as well as the initial temperature profile for these two cases considered (homogeneous ground and heterogeneous multilayer ground). It can be observed that, in case (b), with different ground layers, the evolution of the simulated temperatures is very similar to the experimental ones. However, along the first 3-5 meters, the difference between the simulations and the experimental measurements is higher. This result is due to the fact that the physical phenomena that occur between the ground surface and the top of the BHE are not well known (all the instrumentation equipment is placed in the space between 
the BHE and the surface) and have not been modeled. So the simulated temperature evolution along the first meters is not very accurate. Moreover, the temperature difference in the region located at $25 \mathrm{~m}$ deep is also higher, this fact may be explained because of groundwater advection effects, as it has been explained in Aranzabal, et al. (2016).

On the other hand, in case (a), the calculated temperature along the borehole depth is almost constant for a given time, because a homogeneous ground has been considered.
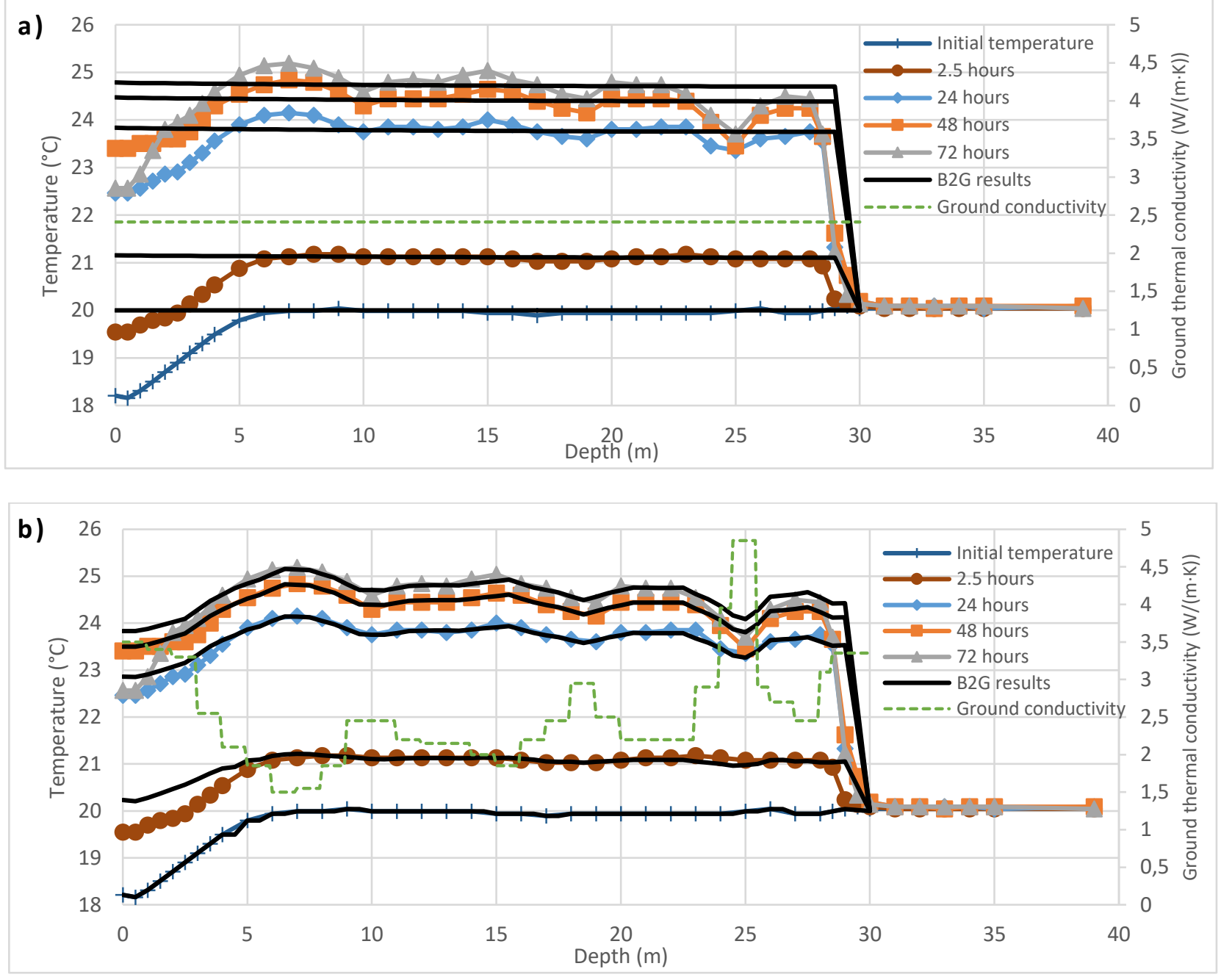

Figure 4 Comparison between the observer tube temperature profile along the borehole depth and the simulated grout nodes' temperatures; experimentally measured (marked lines) and calculated by the B2G model (continuous lines). Values at different heat injection times (initial temperature, 2.5 hours, 24 hours, 48 hours and 72 hours). a) homogeneous ground; b) heterogeneous multi-layer ground.

Taking into account the results presented in this contribution, it is concluded that the B2G dynamic model could be a useful tool to assist the calculation of the ground thermal conductivities along the borehole depth from the measured temperatures along the observer tube, by using an estimated initial conductivity and an approximation algorithm, and applying the same methodology as the one explained in Aranzabal, et al. (2016). Thus, leveraging the low computational cost of the B2G dynamic model which allows making a great number of simulations in a short period of time ( 20 seconds for a 72 hours TRT, 6 seconds for a 24 hours TRT on a modern PC). This way, it would be possible 
to obtain an estimation of the ground thermal conductivity and the overall borehole thermal resistance with a reduction in injection times needed to calculate the ground conductivity. This would mean a reduction of the cost of the TRT and a consequent increase in its economic feasibility. On the other hand, the calculation of the ground thermal conductivity layer by layer can help in the future design of BHEs for the same type of ground, as it is possible to identify substratums with higher thermal conductivity and then size the borehole depth taking advantage of the different layers.

\section{CONCLUSIONS}

This contribution presents the B2G dynamic model as a tool to assist the TRT analysis. The model is able to reproduce a TRT test with a low computational cost (less than 20 seconds for a 72 hours TRT). A new feature was included in the model to consider different ground layers in non homogeneous type of soil, as well as the vertical conduction between the ground and grout nodes. The model was experimentally validated in two different ways: 1) analyzing the temperature evolution along a 72 hours TRT; and 2) analyzing the evolution of the water temperature profile in a multi-layer heterogeneous ground. In 1) the difference between considering a homogeneous ground with a single effective conductivity and initial temperature or a multi-layer ground with different thermal conductivities and initial temperatures, is analyzed. It is concluded that considering an effective ground thermal conductivity is a good estimation presenting a root mean square error of $0.16 \mathrm{~K}$ for a TRT simulation without the need of determining the conductivities layer by layer. In 2) the same effect is analyzed for the water temperature profile along the BHE's depth. In this case, the influence of considering the conductivity of each ground layer results of a higher relevance, specially in order to identify the layers with highest conductivities and to be able to assist in the design of the BHE's depth.

In conclusion, the B2G dynamic model is able to reproduce the behavior of a single U-tube BHE in a multi-layer heterogeneous ground with a low computational cost. This means that it could be a helpful tool in order to estimate the thermal conductivity of different layers in a heterogeneous ground and to assist in the design of future BHE's for a given site.

\section{ACKNOWLEDGMENTS}

The present work has been supported by the European Community Horizon 2020 Program for European Research and Technological Development (2014-2020) inside the framework of the project 656889 - GEOTeCH (Geothermal Technology for Economic Cooling and Heating) and by the Generalitat Valenciana inside the program "Ayudas para la contratación de personal investigador en formación de carácter predoctoral (ACIF/2016/131)".

\section{NOMENCLATURE}

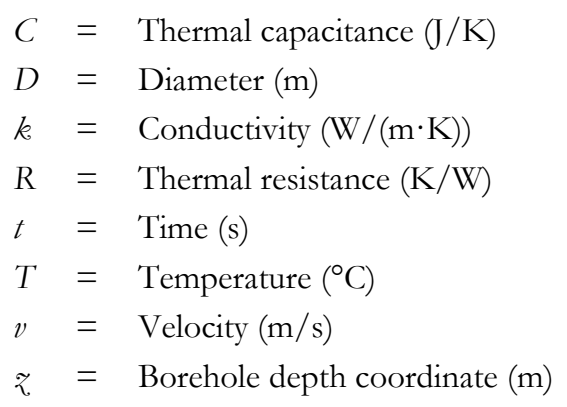

\section{Subscripts}

$$
\begin{aligned}
b b & =\text { Borehole node to borehole node } \\
f & =\text { Fluid } \\
b & =\text { Convection } \\
p p & =\text { Pipe to pipe node }
\end{aligned}
$$




\section{REFERENCES}

Aranzabal, N., Martos, J., Montero, A., Monreal, L., Soret, J., Torres, J. and García-Olcina, R. 2016. Extraction of thermal characteristics of surrounding geological layers of a geothermal heat exchanger by $3 D$ numerical simulations. Applied Thermal Engineering 99: 92-102.

Carslaw, H. S., and Jaeger, J. C. 1959. Conduction of heat in solids. New York, NY, USA: Second ed. Oxford University Press.

Esen, H., Inalli, M. and Esen, Y. 2009. Temperature distributions in boreholes of a vertical ground-coupled heat pump system. Renewable Energy 34: 2672-2679.

Lee, C.K. 2011. Effects of multiple ground layers on thermal response test analysis and ground-source heat pump simulation. Applied Energy 88: 4405-4410.

Pasquier, P. and Marcotte, D. 2012. Short-term simulation of ground heat exchanger with an improved TRCM. Renewable Energy 46: 92-99.

Pasquier, P. 2015. Stochastic interpretation of thermal response test with TRT-SInterp. Computers\&Geosciences 75: 73-87.

De Rosa, M., Ruiz-Calvo, F., Corberán, J. M., Montagud, C., and Tagliafico, L. A. 2015. A novel TRNSYS type for short-term borehole heat exchanger simulation: B2G model. Energy Conversion and Management 100: 347-357.

Ruiz-Calvo, F., De Rosa, M., Acuña, J., Corberán, J. M. and Montagud, C. 2015. Experimental validation of a short-term Boreholeto-Ground (B2G) dynamic model. Applied Energy 140: 210-223.

Ruiz-Calvo, F. 2015. Análisis y modelado de una instalación geotérmica para climatización de un conjunto de oficinas, $\mathrm{PhD}$ Thesis, Universitat Politècnica de València. Available online at: https://riunet.upv.es/handle/10251/54134

Ruiz-Calvo, F., De Rosa, M., Monzó, P., Montagud, C. and Corberán, J. M. 2016. Coupling short-term (B2G model) and long-term (g-function) models for ground source beat exchanger simulation in TRNSYS. Application in a real installation. Applied Thermal Engineering 102: 720-732.

Yang, H., Cui, P. and Fang, Z. 2010. Vertical-borehole ground-coupled heat pumps: a review of models and systems. Applied Energy 87: 16-27. 